\title{
ANALISIS LINE BALANCING PADA BAGIAN SUB FRAME MOTOR MATIC XXX MENGGUNAKAN METODE RANK POSITIONAL WEIGHT
}

\author{
Dimas Rangga Wardhana \\ Teknik Industri, Fakultas Sains dan Teknologi, Universitas Al-Azhar Indonesia \\ e-mail: dimasrnggw@gmail.com
}

\begin{abstract}
ABSTRAK
Sepeda motor merupakan kendaraan bermotor yang sangat digemari masyarakat karena memiliki mobilitas yang tinggi serta harga yang terjangkau. Permintaan yang tinggi menuntut perusahaan-perusahaan sepeda motor untuk memproduksi dalam jumlah banyak dengan kualitas yang baik. Untuk memenuhi target produksi sepeda motor dalam jumlah banyak serta tepat waktu, diterapkanlah metode line balancing di lini produksi agar elemen kerja setiap stasiun memiliki nilai efisiensi yang tinggi serta operator memiliki beban kerja dan waktu yang seimbang sehingga tidak terjadi bottle neck atau penumpukan. Pada kesempatan ini, penulis memilih sebuah perusahaan manufaktur yaitu PT. GG pada divisi assembly unit line b zona sub frame yang menjadi salah satu produsen sepeda motor terkemuka yang berlokasi di Sunter, Jakarta. Dalam laporan ini, penulis menggunakan metode rank positional weight untuk meningkatkan nilai efisiensi tiap stasiun kerja. Setelah dilakukan metode rank positional weight, stasiun kerja yang dimiliki saat ini berjumlah 8 berkurang menjadi 6 stasiun dengan mengurangi 2 stasiun terakhir dan didapat peningkatan efisiensi rata-rata stasiun kerja sebesar $19 \%$.
\end{abstract}

Kata kunci: Efisiensi Lini Produksi, Line Balancing, Rank Positional Weight, Takt Time.

\begin{abstract}
Motorbikes are motorized vehicles that are very popular with the community because they have high mobility and affordable prices. High demand demands motorcycle companies to produce in large quantities with good quality. To meet motorcycle production targets in large quantities and on time, a line balancing method is applied in the production line so that the work elements of each station have high efficiency values and the operator has a balanced workload and time so that there is no bottle neck or buildup. On this occasion, the authors chose a manufacturing company, PT. GG in the assembly line division unit b sub frame zone which is one of the leading motorcycle manufacturers located in Sunter, Jakarta. In this report, the writer uses the rank positional weight method to increase the efficiency value of each work station. After the rank positional weight method is done, the number of work stations that are currently numbered is reduced to 6 stations by reducing the last 2 stations and an increase in the average efficiency of the work station is $19 \%$.
\end{abstract}

Keywords: Efisiensi Lini Produksi, Line Balancing, Rank Positional Weight, Takt Time.

\section{PENDAHULUAN}

Setiap perusahaan manufaktur selalu memiliki tujuan untuk meningkatkan efisiensi pada kegiatan produksinya. Efisiensi dilihat dari seberapa baik sumber daya digunakan dalam aktivitas tertentu [1]. Dalam dunia manufaktur, efisiensi berkaitan dengan banyak kegiatan, salah satunya adalah dalam kegiatan produksi. Produksi merupakan pertanggungjawaban dalam pengolahan dan perubahan masukan (inputs) menjadi keluaran (outputs) berupa barang atau jasa yang akan memberikan hasil pendapatan bagi perusahaan [2].

Pada kesempatan ini, penulis memilih untuk melaksanakan praktek kerja lapangan pada sebuah perusahaan manufaktur yaitu PT. GG. PT. GG merupakan salah satu produsen sepeda motor terbesar di Indonesia yang berlokasi di Sunter, Jakarta. Permintaan yang sangat tinggi menuntut PT. GG untuk memenuhi permintaan dengan memproduksi dalam jumlah banyak dengan kualitas yang baik. Untuk bisa memproduksi sepeda motor dalam jumlah besar serta tepat waktu, diterapkanlah metode line balancing di lini produksi agar setiap stasiun kerja yang ada di lini produksi dapat menyelesaikan pekerjaan sesuai dengan 


\section{Dimas Rangga Wardhana}

waktu baku yang telah ditentukan. Selain itu, line balancing juga menentukan serta menyeimbangkan elemen kerja setiap stasiun agar setiap stasiun memiliki nilai efisiensi yang tinggi serta operator memiliki beban kerja dan waktu yang seimbang sehingga tidak terjadi bottle neck atau penumpukan. Dalam laporan ini, penulis memfokuskan analisis line balancing pada divisi assembly unit line b zona sub frame.

Dalam menyusun laporan ini, penulis melakukan pengumpulan data berupa waktu siklus, jumlah stasiun kerja, dan elemen-elemen kerja yang ada pada tiap stasiun kerja. Setelah data terkumpul, data diolah menggunakan metode line balancing untuk mendapatkan beban kerja yang seimbang dan nilai efisiensi yang maksimal. Dari hasil pengolahan data, penulis memberi kesimpulan dan saran berdasarkan analisis yang telah dibuat.

\section{METODE PENELITIAN}

\section{Line Balancing}

Tujuan line balancing adalah untuk memperoleh suatu arus produksi yang lancar dalam rangka memperoleh utilisasi yang tinggi atas fasilitas, tenaga kerja, dan peralatan melalui penyeimbangan waktu kerja antar work station, dimana setiap elemen tugas dalam suatu kegiatan produksi dikelompokkan sedemikian rupa dalam beberapa stasiun kerja yang telah ditentukan sehingga diperoleh keseimbangan waktu kerja yang baik, sedangkan tujuan dari lintasan produksi yang seimbang adalah menyeimbangkan beban kerja yang dialokasikan pada setiap work station sehingga setiap work station selesai pada waktu yang seimbang dan mencegah terjadinya bottle neck. Bottle neck adalah suatu operasi yang membatasi output dan frekuensi produksi [3].

\section{Rank Positional Weight}

Metode Rank Positional Weights (RPW) Metode ini merupakan metode gabungan antara metode Large Candidat Ruler dengan metode region approach. nilai RPW merupakan perhitungan antara elemen kerja tersebut dengan posisi masing-masing elemen kerja dalam precedence diagram. Langkah-langkah dari metode RPW adalah sebagai berikut [4]:

1. Membuat precedence diagram atau diagram jaringan kerja dari OPC

2. Menghitung waktu siklus

3. Membuat matiks lintasan berdasarkan precedence diagram.

4. Menghitung bobot posisi tiap operasi yang dihitung berdasarkan jumlah waktu operasi tersebut dan operasi-operasi yang mengikutinya

5. Mengurutan operasi-operasi mulai bobot operasi terbesar sampai dengan terkecil

6. Menghitung jumlah stasiun kerja minimum

7. Membuat flow diagram untuk stasiun kerja minimum tersebut lalu lakukan pembebanan operasi pada stasiun kerja mulai dari operasi dari bobot operasi terbesar sampai dengan terkecil, dengan kriteria total waktu operasi lebih kecil dari waktu siklus yang diinginkan

8. Melakukan trial and error untuk mendapatkan efisiensi lintasan yang paling tinggi.

\section{Efisiensi Lintasan Produksi (Line Efficiency)}

Line Efficiency merupakan rasio dari total waktu stasiun kerja dibagi dengan siklus dikalikan jumlah stasiun kerja [5]. Line efficiency dapat dirumuskan sebagai berikut:

$$
\text { Line Efficiency }=\frac{\sum_{i=1}^{K} S T_{i}}{K(C T)} \times 100
$$

Keterangan:

STi = Waktu stasiun kerja dari ke-i 
$\sum \mathrm{K}=$ Jumlah stasiun kerja

$\mathrm{CT}=$ Waktu siklus

\section{Smoothest Indeks}

Smoothest Indeks merupakan indeks yang menunjukkan kelancaran relatif dari penyeimbangan lini perakitan tertentu.

$$
S I=\sum_{i=1}^{K}(C T \max -S T i)^{2}
$$

Keterangan:

SI $=$ Smoothest Indeks

CTmax $=$ Maksimum waktu di stasiun

\section{HASIL DAN PEMBAHASAN}

Data yang di gunakan dalam penelitian ini meliputi data stasiun kerja pada lantai produksi yang berisi elemen kerja tiap stasiun kerja dapat dilihat pada Gambar 1, data waktu setiap elemen kerja dapat dilihat pada Lampiran 1. Data gerakan setiap stasiun dapat dilihat pada Lampiran 2. Pengambilan data waktu per elemen kerja diambil sebanyak 30 kali. takt time dan precedence diagram. Pada lini produksi ini terdapat 8 stasiun yang terdiri dari stasiun 600, 601, 602, 603, 605, 465, 702 dan 704. Data waktu setiap stasiun dengan takt time sebesar 20 detik. Proses produksi motor matic XXX berlangsung sesuai dengan precedence diagram pada Gambar 2.

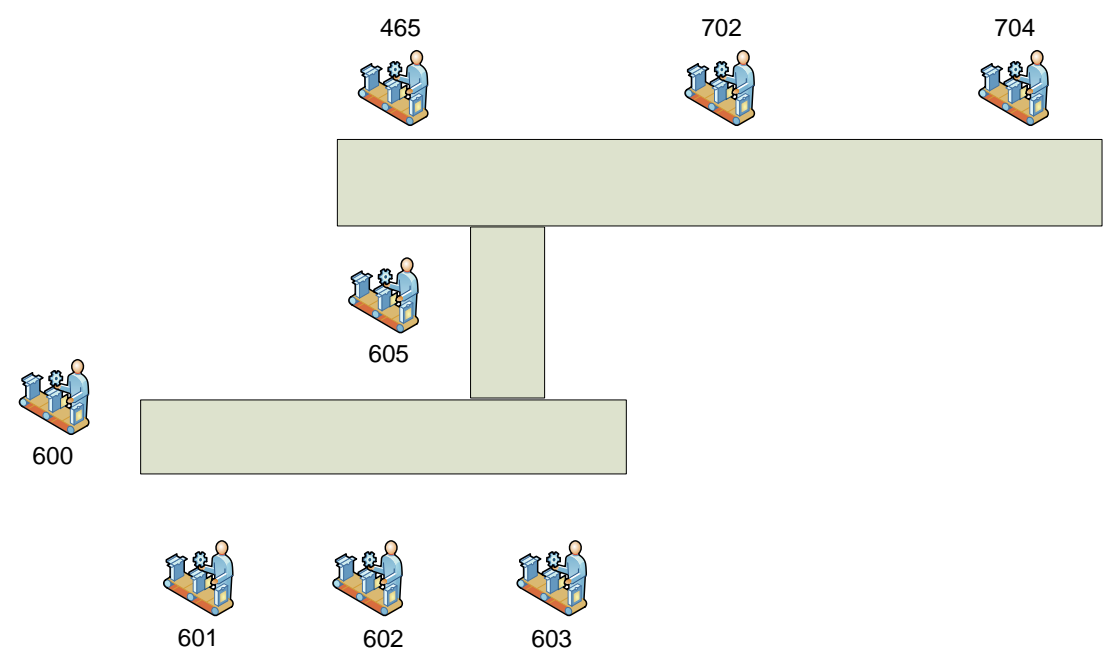

Gambar 1. Letak Stasiun kerja Pada Lantai Produksi

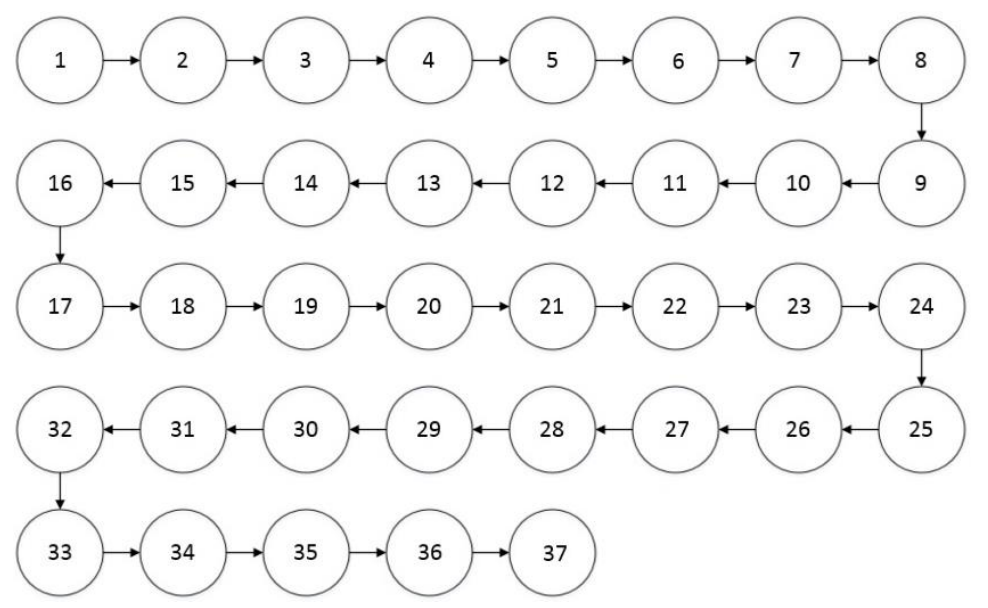

Gambar 2. Precedence Diagram 


\section{Dimas Rangga Wardhana}

\section{Hasil Perhitungan Waktu Rata-rata \& Waktu Total Tiap Stasiun}

Proses perhitungan waktu rata-rata bisa dilihat pada lampiran 3 yang berisi waktu tiap stasiun serta waktu rata-ratanya beserta waktu tercepat dan terlama dan jumlah waktu tiap stasiun.

\section{Hasil Perhitungan Stasiun Kerja Minimal}

Perhitungan stasiun kerja minimal dilakukan dengan persamaan:

$$
\text { Jumlah Stasiun Minimal }=\frac{\text { Jumlah Waktu Keseluruhan }}{\text { Takt Time }}
$$

Dari persamaan di atas didapatkan stasiun kerja minimal 4,76. Pada lini produksi motor matic XXX memiliki stasiun kerja sebanyak 8 .

\section{Hasil Perhitungan Efisiensi Lini Produksi}

Perhitungan efisiensi lini produksi dilakukan dengan rumus:

Efisiensi Lini Produksi $=\frac{\text { Jumlah Waktu Keseluruhan }}{\text { (Jumlah Stasiun } \times \text { Takt Time })} \times 100 \%$

Dari hasil perhitungan efisiensi lini produksi, pada lini produksi motor matic XXX didapatkan efisiensi lini produksi sebesar $60 \%$.

\section{Hasil Perhitungan Efisiensi Setiap Stasiun Kerja Sebelum RPW}

Perhitungan efisiensi setiap stasiun kerja dilakukan dengan rumus:

$$
\text { Efisiensi Stasiun Kerja }=\frac{\text { Total Waktu Per Stasiun }}{\text { Takt Time }} \times 100 \%
$$

Berdasarkan hasil perhitungan didapatkan hasil efisiensi stasiun kerja yang di tunjukkan pada Tabel 1 didapatkan efisiensi tiap stasiun dari stasiun kerja. Pada Tabel 2, didapatkan elemen kerja dan waktu proses tiap stasiun kerja sebelum menggunakan Metode Rank Positional weight. Diagram efisiensi tiap stasiun kerja dapat dilihat pada Gambar 3.

\begin{tabular}{lc}
\multicolumn{2}{c}{ Tabel 1. Efisiensi Tiap Stasiun Kerja } \\
\hline Efisiensi WS 600 & $64 \%$ \\
Efisiensi WS 601 & $59 \%$ \\
Efisiensi WS 602 & $69 \%$ \\
Efisiensi WS 603 & $31 \%$ \\
Efisiensi WS 605 & $59 \%$ \\
Efisiensi WS 465 & $59 \%$ \\
Efisiensi WS 702 & $63 \%$ \\
Efisiensi WS 704 & $72 \%$ \\
\hline Rata-rata Efisiensi Work Station & $60 \%$ \\
\hline
\end{tabular}

Tabel 2. Elemen Kerja Tiap Stasiun Kerja Sebelum RPW

\begin{tabular}{ccc}
\hline Stasiun & Proses & Waktu \\
\hline 600 & $1,2,3,4,5$ & 12,88 \\
601 & $6,7,8,9,10$ & 11,79 \\
602 & 11,12 & 13,72 \\
603 & $13,14,15,16,17,18$ & 6,26 \\
605 & $19,20,21,22$ & 11,77 \\
465 & $23,24,25,26$ & 11,73 \\
702 & $27,28,29,30,31,32$ & 12,63 \\
704 & $33,34,35,36,37$ & 14,49 \\
\hline \multicolumn{3}{c}{ Total Waktu } \\
\hline
\end{tabular}




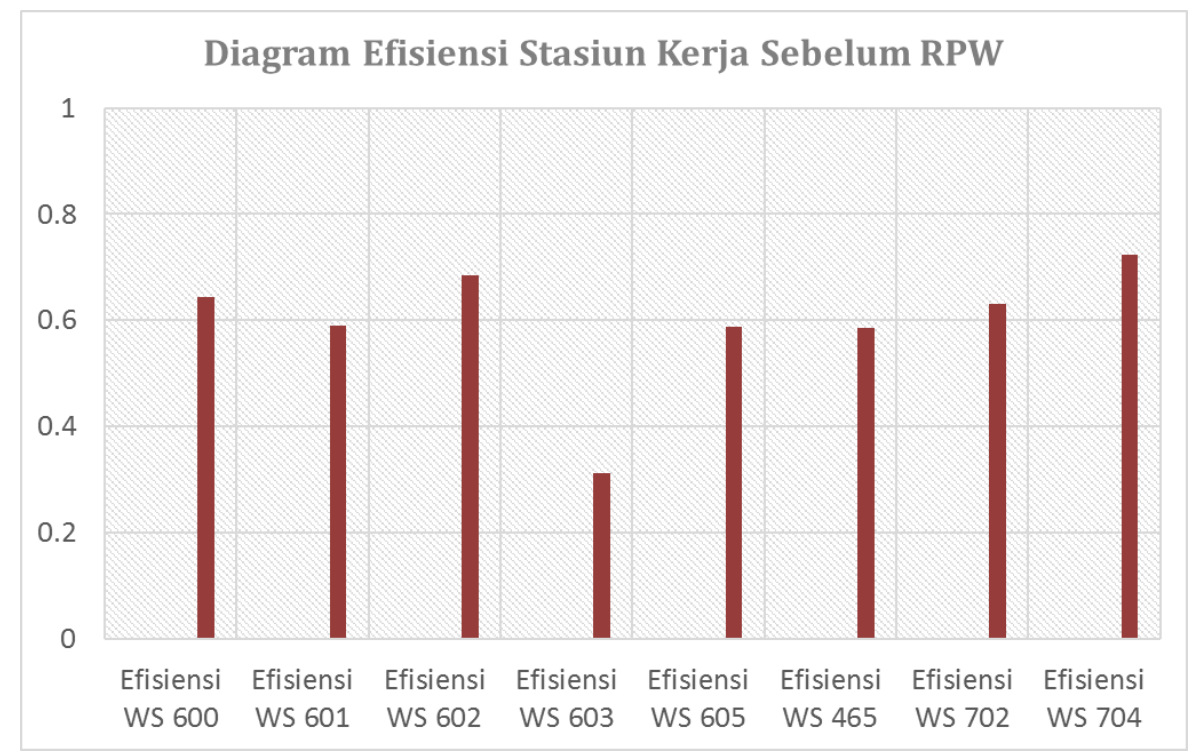

Gambar 3. Diagram Efisiensi Stasiun Kerja Sebelum RPW

\section{Hasil Perhitungan Efisiensi Setiap Stasiun Kerja Setelah RPW}

Metode RPW digunakan untuk membagi bobot stasiun kerja agar tiap stasiun kerja memiliki bobot yang seimbang satu sama lainnya. Hasil perhitungan dari Metode RPW bisa dilihat pada Tabel 2. Dari metode ini dapat dilihat bahwa elemen kerja no. 19 yang berawal ada di stasiun 605 berpindah ke stasiun 603, lalu elemen kerja no. 23 yang berawal ada di stasiun 465 berpindah ke stasiun 605. Dari perpindahan elemen kerja tersebut, didapatkan perubahan efisiensi tiap stasiun kerja yang dapat dilihat pada Tabel 3

\begin{tabular}{|c|c|}
\hline Efisiensi WS 600 & $75 \%$ \\
\hline Efisiensi WS 601 & $48 \%$ \\
\hline Efisiensi WS 602 & $100 \%$ \\
\hline Efisiensi WS 603 & $67 \%$ \\
\hline Efisiensi WS 605 & $99 \%$ \\
\hline Efisiensi WS 465 & $87 \%$ \\
\hline Rata-Rata Efisiensi Work Station & $79 \%$ \\
\hline
\end{tabular}

Pada Tabel 3, dapat dilihat setelah menggunakan metode RPW, didapatkan kenaikan rata-rata efisiensi work station yang berawal dari $60 \%$ menjadi $79 \%$. Perubahan ini terjadi karena penggabungan beberapa elemen kerja pada satu stasiun kerja sehingga terjadi pengurangan stasiun kerja yang awalnya memiliki 8 stasiun kerja menjadi 6 stasiun kerja. Pengurangan stasiun kerja tersebut antara lain stasiun kerja 702 dan stasiun kerja 704 . Pengurangan stasiun kerja beserta elemen kerja dapat dilihat pada Tabel 4.

\begin{tabular}{|c|c|c|}
\hline Stasiun & Proses & Waktu \\
\hline 600 & $1,2,3,4,5,6,7$ & 15,04 \\
\hline 601 & $8,9,10$ & 9,63 \\
\hline 602 & $11,12,13,14,15,16,17,18$ & 19,98 \\
\hline 603 & $19,20,21,22,23$ & 13,39 \\
\hline 605 & $24,25,26,27,28,29,30$ & 19,84 \\
\hline \multirow[t]{2}{*}{465} & $31,32,33,34,35,36,37$ & 17,4 \\
\hline & Total Waktu & 95,28 \\
\hline
\end{tabular}




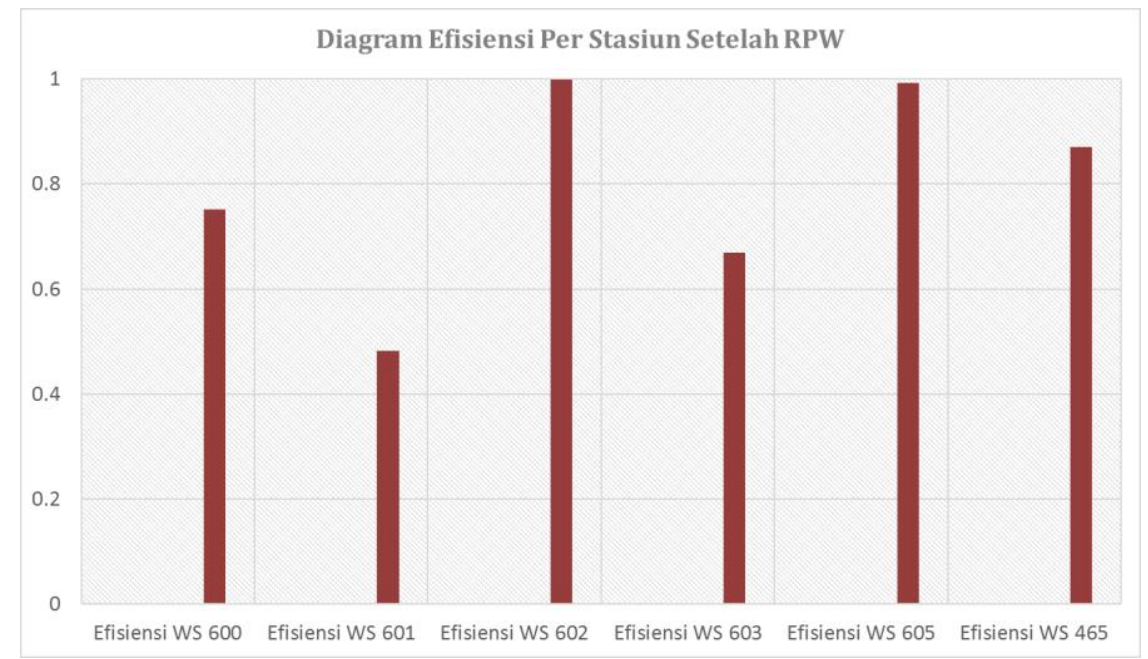

Gambar 6. Diagram Efisiensi Stasiun Kerja Setelah RPW

\section{KESIMPULAN}

Dari analisis yang dilakukan, dapat disimpulkan bahwa nilai efisiensi pada beberapa stasiun kerja masih dapat ditingkatkan. Efisiensi stasiun kerja 600 meningkat $11 \%$, efisiensi stasiun kerja 601 menurun 11\%, stasiun kerja 602 meningkat 31\%, stasiun kerja 603 meningkat 36\%, stasiun kerja 605 meningkat 40\%, stasiun kerja 465 meningkat $28 \%$. Stasiun kerja yang dimiliki saat ini berjumlah 8, dengan mengurangi 2 stasiun terakhir menggunakan metode rank positional weight, didapat peningkatan efisiensi rata-rata stasiun kerja sebesar 19\%. Dengan melakukan perpindahan elemen kerja nomor 6016 dan 6017 yang berada di stasiun kerja 601 ke stasiun kerja 600. Efisiensi stasiun kerja 600 mengalami peningkatan sebesar $11 \%$. Melakukan perpindahan elemen kerja nomor 60313, 60314, 60315, 60316, 60317, dan 60318 yang berada di stasiun kerja 603 ke stasiun kerja 602. Efisiensi stasiun kerja 602 mengalami peningkatan sebesar $31 \%$. Melakukan perpindahan elemen kerja nomor 60519, 60520, 60521, 60522, 60523, dan 46523 yang berada di stasiun kerja 605 dan 465 ke stasiun kerja 603. Efisiensi stasiun kerja 602 mengalami peningkatan sebesar $31 \%$. Melakukan perpindahan elemen kerja nomor 46524, 46525, 46526, 70227, 70228, 70229, dan 70230 yang berada di stasiun kerja 465 dan 702 ke stasiun kerja 605. Efisiensi stasiun kerja 605 mengalami peningkatan sebesar $40 \%$. Melakukan perpindahan elemen kerja nomor 46524, 46525, 46526, 70227, 70228, 70229, dan 70230 yang berada di stasiun kerja 465 dan 702 ke stasiun kerja 605. Efisiensi stasiun kerja 605 mengalami peningkatan sebesar 40\%. Melakukan perpindahan elemen kerja nomor 70231, 70232, 70433, 70434, 70435, 70436, dan 70437 yang berada di stasiun kerja 702 dan 704 ke stasiun kerja 465. Efisiensi stasiun kerja 465 mengalami peningkatan sebesar $28 \%$.

\section{DAFTAR PUSTAKA}

[1].Daellenbach, Hans G. dan Donald C. McNickle. 2005. Management Science: Decision Making Through Systems Thinking. New Zealand: Palgrave Macmillan.

[2].Assauri, Sofjan. 1993. Manajemen Produksi. Edisi 3. Lembaga Penerbit Fakultas Ekonomi Universitas Indonesia, Jakarta.

[3].Malave, C. 2000. Approach to Line Balancing Comsoal \& RPW. Texas: A\&M University.

[4].Heizer, J. dan Render, B. 2006. Manajemen Operasi, Edisi 7. Jakarta: Salemba Empat.

[5].Baroto, T. 2002. Perencanaan dan Pengendalian Produksi. Indonesia: Ghalia. 


\section{Lampiran 1}

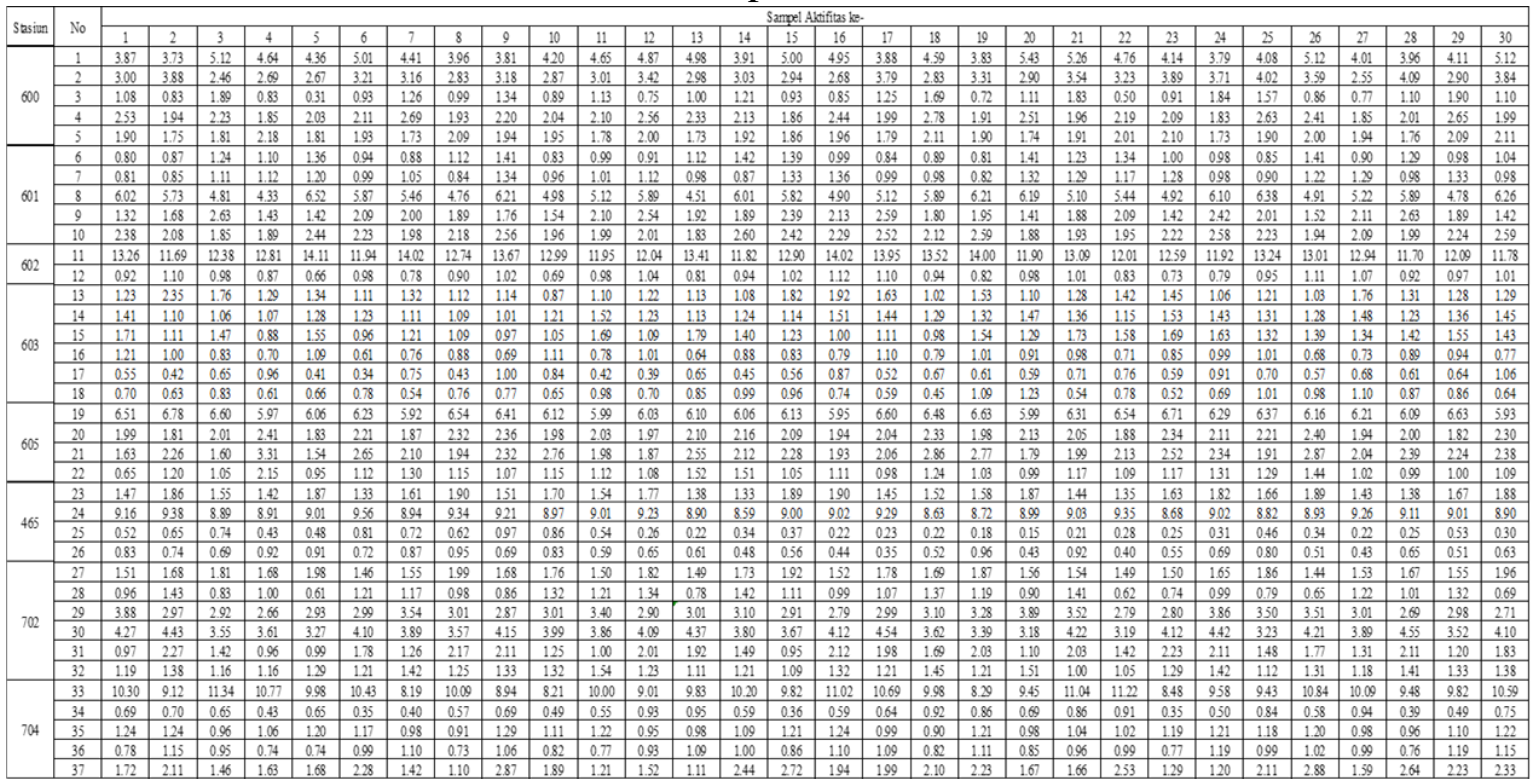

\section{Lampiran 2}

\begin{tabular}{|c|c|c|}
\hline Stasiun & No & Elemen Kerja \\
\hline \multirow{5}{*}{600} & 1 & $\begin{array}{l}\text { Ambil \& posisikan BODY COMP, FRAME pada jig M/C Numbering tipe K61G, } \\
\text { clamp dengan menekan Push Button Start (hijau) }\end{array}$ \\
\hline & 2 & $\begin{array}{l}\text { Ambil Barcode Tag, lalu scan barcode untuk memulai proses marking numbering, } \\
\text { pastikan barcode sesuai tipe }\end{array}$ \\
\hline & 3 & Tempelkan satu bagian barcode tag di pipe $R / L$ sub frame body \\
\hline & 4 & Selipkan sisa barcode tag di stay step bagian tengah floor frame body \\
\hline & 5 & $\begin{array}{l}\text { Cek hasil marking numbering, hasil marking terlihat jelas dengan jumlah karakter } 17 \\
\text { digit }\end{array}$ \\
\hline \multirow{7}{*}{601} & 6 & Pasang pada jig M/C Press (pada pin press upper) \\
\hline & & $>$ RACE, STRG, TOP BALL, masukkan sampai tettahan ball catcher \\
\hline & 7 & Pasang pada jig MC Press (pada pin press lower) \\
\hline & & $>$ RACE, STRG, TOP BALL, masukkan sampai tettahan ball catcher \\
\hline & 8 & Ambil BODY COMP, FRAME dari shooter lalu press di M/C Press Cone Race \\
\hline & 9 & $\begin{array}{l}\text { Lapiskan cairan Clear pada marking numbering di BODY COMP, FRAME (stay } \\
\text { seat rear) }\end{array}$ \\
\hline & 10 & Ambil BODY COMP, FRAME dari M/C press \& letakkan di shooter \\
\hline \multirow{3}{*}{602} & 11 & $\begin{array}{l}\text { Beri Grease pada RACE STEERING BOTTOM BALL. Pasang pada RACE } \\
\text { STEERING BOTTOM BALL di BODY COMP, FRAME lubang headpipe bagian } \\
\text { bawah : }\end{array}$ \\
\hline & & $\begin{array}{l}\text { 7 BALL, STEEL, } 6(3 / 16) \text { pada Head pipe under dicampur dengan grcase dari platc } \\
\text { (special equipment) Ratakan pemasangan BALL, STEEL, } 6 \text { dan grease }\end{array}$ \\
\hline & 12 & Geser FRAME BODY ke stasiun berikutnya \\
\hline \multirow{8}{*}{603} & 13 & Angkat FRAME BODY dari shooter \& letakkan pada jig conveyor sub frame \\
\hline & 14 & $\begin{array}{l}\text { Ambil SET ILLUST, RR FENDER ASSY di conveyor lalu pasang pada FRAME } \\
\text { BODY sisi belakang kaitkan }\end{array}$ \\
\hline & 15 & $\begin{array}{l}\text { Pindahkan Key Set (sw combo lock + Shutter Key) dari conveyor ke SET ILLUST } \\
\text { ASSY sisi atas }\end{array}$ \\
\hline & 16 & $\begin{array}{l}\text { Pasang pada SET ILLUST, RR FENDER ASSY dan FRAME BODY sisi depan } \\
\text { (dari arah atas): }\end{array}$ \\
\hline & & 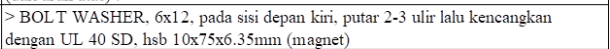 \\
\hline & 17 & $\begin{array}{l}\text { Pasang pada SET ILLUST, RR FENDER ASSY dan FRAME BODY sisi depan } \\
\text { (dari arah atas): }\end{array}$ \\
\hline & & $\begin{array}{l}\text { > BOL T WASHER, 6x12, pada sisi depan kanan, putar 2-3 ulir lalu kencangkan } \\
\text { dengan UL } 40 \text { SD, hsb 10x75x6.35mm (magnet) }\end{array}$ \\
\hline & 18 & $\begin{array}{l}\text { Cek dan pastikan karakter (angka \& huruf) hasil numbering di BODY COMP, } \\
\text { FRAME seat rear, digit ke } 15-17\end{array}$ \\
\hline \multirow{6}{*}{605} & 19 & Pasang pada FRAME BODY (belakang): \\
\hline & & $>$ WASHER PLAIN $10 \mathrm{MM}$ \\
\hline & & $>$ NUT, HEX., CAP, 10 MM, putar 3 ulir \\
\hline & 20 & $\begin{array}{l}\text { Kencangkan NUT, HEX., CAP, } 10 \text { MM pada CUSHION ASSY, REAR (upper) } \\
\text { dan FRAME BODY dengan UL } 60 \text {, hs } 14 \times 75 \times 9.5 \mathrm{~mm}\end{array}$ \\
\hline & 21 & $\begin{array}{l}\text { Cek \& pastikan karakter (angka \& huruf) hasil numbering di BODY COMP, } \\
\text { FRAME seat rear, digit ke 12-14 }\end{array}$ \\
\hline & 22 & $\begin{array}{l}\text { Ambil REFLEX REFLEC TOR, RR lalu pasang pada FENDER ASSY, RR. Pastikan } \\
\text { hasil pemasangan lurus dan simetri atas-bawah dan kanan-kiri }\end{array}$ \\
\hline
\end{tabular}

\begin{tabular}{|c|c|c|}
\hline \multirow{7}{*}{465} & 23 & Ambil KEY SET lalu letakkan pada meja jig setting rear fender \\
\hline & 24 & $\begin{array}{l}\text { Ambil COVER, SEAT LOCK ASSY lalu letakkan pada meja jig setting seat lock lalu } \\
\text { pasang: }\end{array}$ \\
\hline & & $>$ SEAT LOCK COMP \\
\hline & & $>$ WASHER, SEAT LOCK \\
\hline & & $>$ SET, SPG LOCK KEY, tekan sampai mengunci \\
\hline & 25 & Lepaskan key set dari seat lock comp \\
\hline & 26 & Letakkan cover seat lock assy set di stasiun 702 \\
\hline \multirow{7}{*}{702} & 27 & $\begin{array}{l}\text { Ambil FENDER ASSY, RR dari kereta lahu tempatkan pada jig sub mark honda } \\
\text { (FENDER ASSY, RR) }\end{array}$ \\
\hline & 28 & $\begin{array}{l}\text { Assy FENDER ASSY, RR dan COVER, SEAT LOCK ASSY + KEY SET di jig } \\
\text { setting rear fender }\end{array}$ \\
\hline & 29 & $\begin{array}{l}\text { Pasang pada FENDER ASSY, RR dan COVER, SEAT LOCK ASSY SET (dari } \\
\text { atas): }\end{array}$ \\
\hline & & $\begin{array}{l}\text { > SCREW, VISOR SPL SET (2) sisi depan \& belakang, lalu kencangkan dengan UL } \\
40 \mathrm{SD} \text {, sdb } 2 \times 75 \times 0.635 \mathrm{~mm} \text { (magnet) }\end{array}$ \\
\hline & 30 & $\begin{array}{l}\text { Bersihkan FENDER ASSY, RR sisi belakang pada area pemasangan mark honda } \\
\text { dengan kain lap/majun }\end{array}$ \\
\hline & 31 & $\begin{array}{l}\text { Pastikan hasil pemasangan MARK, HONDA } 60 \mathrm{MM} \text {, lurus lalu lakukan penekanan } \\
\text { kembali dengan menggunakan squash }\end{array}$ \\
\hline & 32 & Buka stiker premasking MARK, HONDA $60 \mathrm{MM}$ \\
\hline \multirow{9}{*}{704} & 33 & Pasang pada FRAME BODY (headpipe): \\
\hline & & $>$ KEY SET (pin harus masuk ke lubang bracket) \\
\hline & & $>$ SCREW, FLAT U LOCK $6 \times 12$, pasang bagian atas, putar 2-3 ulir \\
\hline & & $\begin{array}{l}\text { > SCREW, FLAT U LOCK } 6 \times 12 \text {, pasang bagian bawah, kencangkan sisiatas dan } \\
\text { bawah dengan UL } 40 \mathrm{D} \text {, sdb } 3 \times 100 \times 6.35 \mathrm{~mm} \text {, (pengencangan dilakukan setelah } \\
\text { kedua SCREW terpasang) }\end{array}$ \\
\hline & 34 & Check fungsi lock pada KEY SET (pin harus dapat bergerak sliding) \\
\hline & 35 & Olesi di Bolt Cushion atas yang menempel di frame body dengan Vegetable Soap \\
\hline & 36 & Ambil CUSHION ASSY, REAR, dari kereta \\
\hline & 37 & Pasang pada BODY COMP, FRAME (bagian belakang): \\
\hline & & $>$ CUSHION ASSY, REAR, masukkan ke plate stay rear cushion dari arah dalam \\
\hline
\end{tabular}


Analisis Line Balancing pada Bagian Sub Frame Motor Matic XXX Menggunakan Metode Rank Positional Weight

\section{Dimas Rangga Wardhana}

\section{Lampiran 3}

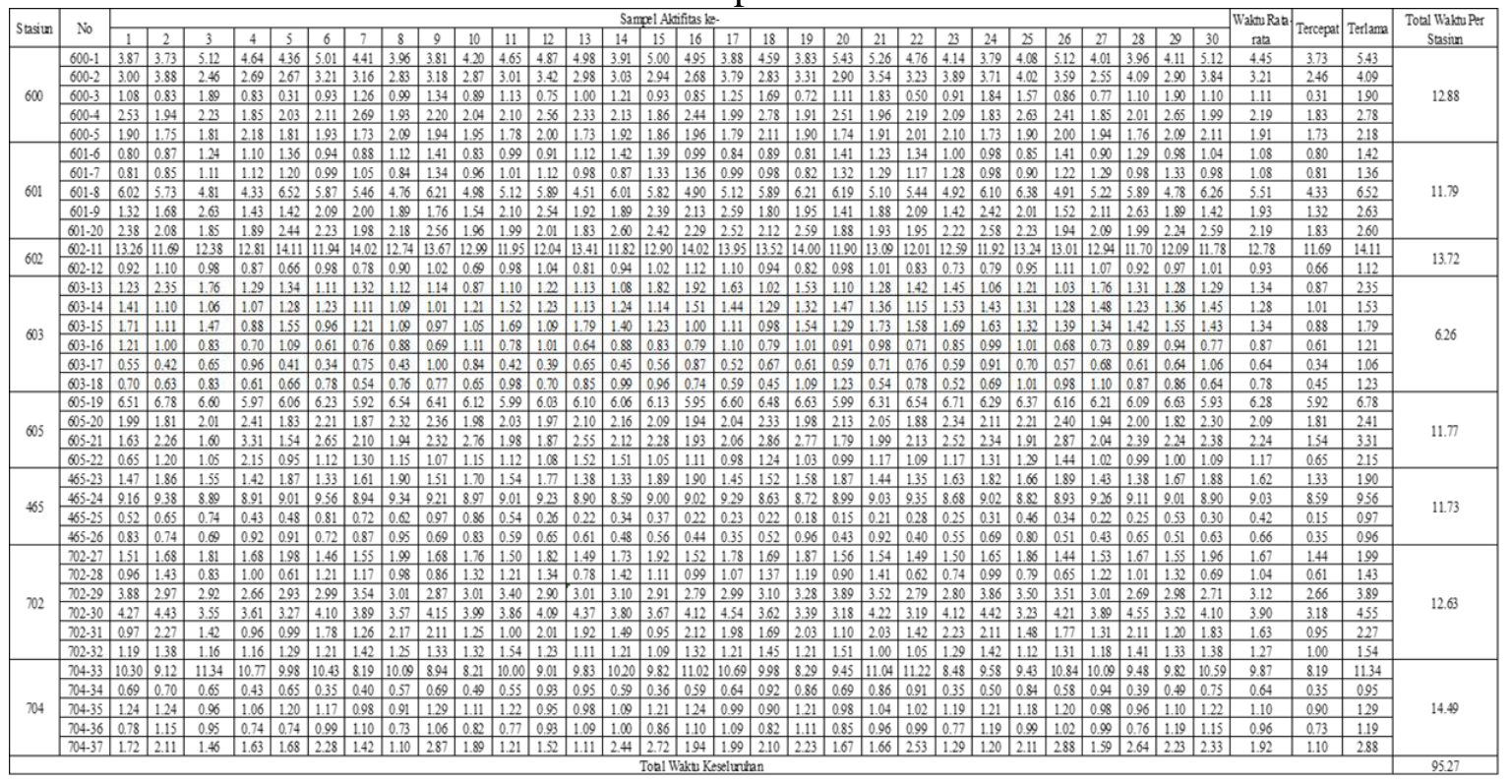

\section{Lampiran 4}

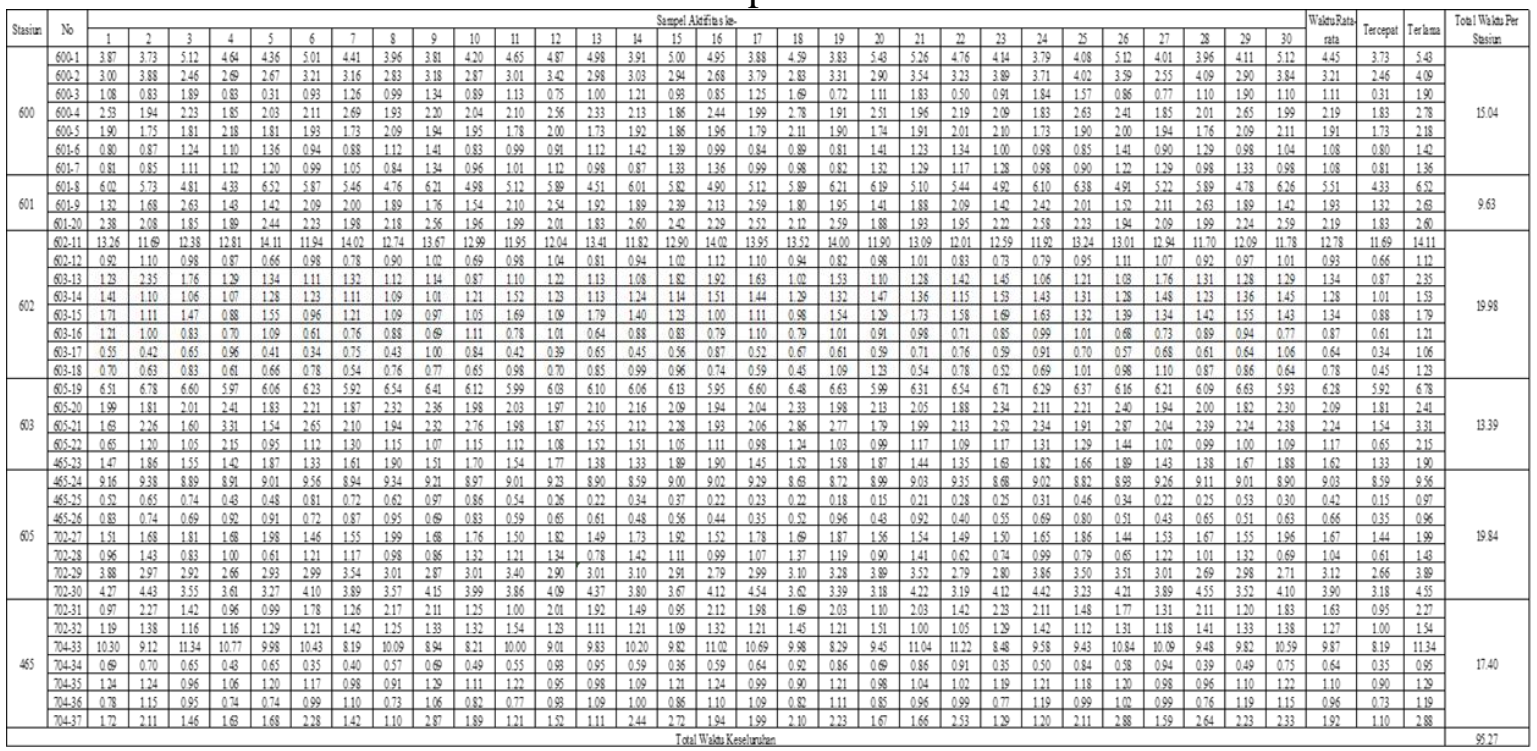

